\title{
Rubella Infection
}

National Cancer Institute

\section{Source}

National Cancer Institute. Rubella Infection. NCI Thesaurus. Code C85051.

A viral infection caused by the rubella virus. It is initially manifested with flu-like symptoms that last one or two days, followed by the development of a characteristic red rash which lasts from one to five days. The rash first appears in the neck and face. It subsequently spreads to the rest of the body. 